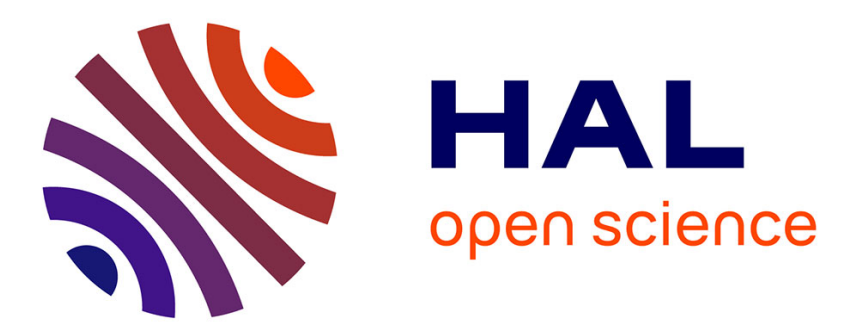

\title{
Exciton saturation and field screening in InGaAs/InGaAsP multiple quantum wells
}

T. Tütken, B. Hawdon, E. Scheuble, M. Zimmermann, P. König, A. Hangleiter, V. Härle, F. Scholz

\section{- To cite this version:}

T. Tütken, B. Hawdon, E. Scheuble, M. Zimmermann, P. König, et al.. Exciton saturation and field screening in InGaAs/InGaAsP multiple quantum wells. Journal de Physique IV Proceedings, 1993, 03 (C5), pp.C5-257-C5-260. 10.1051/jp4:1993550 . jpa-00251636

\section{HAL Id: jpa-00251636 https://hal.science/jpa-00251636}

Submitted on 1 Jan 1993

HAL is a multi-disciplinary open access archive for the deposit and dissemination of scientific research documents, whether they are published or not. The documents may come from teaching and research institutions in France or abroad, or from public or private research centers.
L'archive ouverte pluridisciplinaire HAL, est destinée au dépôt et à la diffusion de documents scientifiques de niveau recherche, publiés ou non, émanant des établissements d'enseignement et de recherche français ou étrangers, des laboratoires publics ou privés. 


\title{
Exciton saturation and field screening in InGaAs/InGaAsP multiple quantum wells
}

\section{T. TÜTKEN, B.J. HAWDON, E. SCHEUBLE, M. ZIMMERMANN, P. KÖNIG, A. HANGLEITER, V. HÄRLE and F. SCHOLZ}

\author{
4. Physikalisches Institut, Universität Stuttgart, Pfaffenwaldring 57, 7000 Stuttgart 80, Germany
}

\begin{abstract}
We performed differential transmission spectroscopy and time resolved pump probe measurements on biased InGaAs/InGaAsP multiple quantum well structures. At low carrier excitation levels we observe a shift in the energy of the excitonic absorption resonance caused by the photogenerated carriers screening the applied electric field within the quantum wells. Increasing the pump power the exciton transmission energy blue shifts until it reaches the zero internal field energy position. For our pump-probe measurements field screening dominates at pump powers lower than $50 \mathrm{~W} / \mathrm{cm}^{2}$ while at higher powers exciton saturation becomes dominant. We deduce a saturation intensity of $250 \mathrm{~W} / \mathrm{cm}^{2}$.
\end{abstract}

\section{Introduction}

Multiple quantum well structures are considered serious contenders in a variety of optoelectronic applications for example MQW modulators $[1,2]$. These devices can be optimized changing structural parameters like widths and compositions of the barriers or wells [3]. But there are modifications of the absorption of those structures caused by the excitation intensity like field screening[4] and exciton saturation $[5,6]$ which limit the switching efficiency. Due to this it is important to understand these additional effects. There have also been reports showing that the high speed characteristics of external modulators are influenced by optically injected carriers $[2,7,8]$.

In this paper the excitation depend absorption properties are investigated using static differential transmission and dynamic pump-probe measurements. We investigated the differential transmission signal in dependence of the intensity of a separate excitation YAG laser beam which excites the multi quantum well and the barrier region.

We investigated p-i-n InGaAs $/ \operatorname{InGaAsP} / \ln \mathrm{P}\left(E_{G}(\operatorname{InG} G A s P)=1.07 \mathrm{eV}\right)$ quantum well structures grown by low pressure MOVPE. The number of wells was $10\left(L_{z}=10 \mathrm{~nm}\right)$ and the barriers and confinement layers are $10 \mathrm{~nm}$ and $100 \mathrm{~nm}$ long, respectively.

\section{Differential Transmission Measurements under CW Optical Excitation}

We performed standart differential transmission measurements varing the external voltage under different excitation conditions. Fig. 1 shows the spectra for three different excitation powers at a applied voltage of $U_{0}=-1 \mathrm{~V}$ and a voltage modulation of $\Delta U=2 \mathrm{~V}$ peak to peak. We recognize a shift in the position of the exciton which is given by a change in the zero crossing point. Increasing the excitation power density from $0 \mathrm{~mW} / \mathrm{cm}^{2}$ to $1200 \mathrm{~mW} / \mathrm{cm}^{2}$ we obtain a shift of $10 \mathrm{meV}$ to higher 


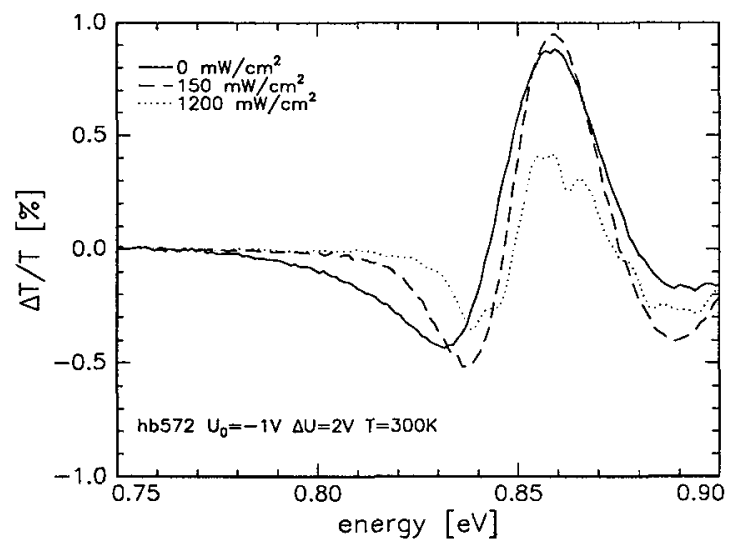

Figure 1: Voltage modulated differential transmission signal for three different excitation power densities. Increasing the power density we find a blue shift in the exciton energy and a decrease in the modulation depth and modulating wavelength region.

energy. In addition we see that the modulation depth and the wavelength region in which the modulation occurs decrease with increasing excitation power.

These experimental results are caused by the separation of the photogenerated carriers in the intrinsic field of the $\mathrm{p}-\mathrm{i}-\mathrm{n}$ structure of about $10^{4} \mathrm{~V} / \mathrm{cm}$. The field screening reduces the electric field in the multi quantum well region whereby the electric field in the confinement layers increases. The reduced electric field in the MQW region gives the reason for the blue shift in the exciton energy. Because of the screening the external voltage modulation gets less and less effective and at high excitation power the screened MQW region is hardly reacting. Due to this the decrease in the modulation depth and the wavelength region in which the modulation occurs can also be explained.

Modulating a low power cw-YAG beam at zero applied voltage we investigated the power dependence of the differential transmission signal. We observe, shown in Fig. 2, only negative signals decreasing with YAG-power. This is caused by the blue shift of the exciton position and therefore an increase of the absorption coefficient.

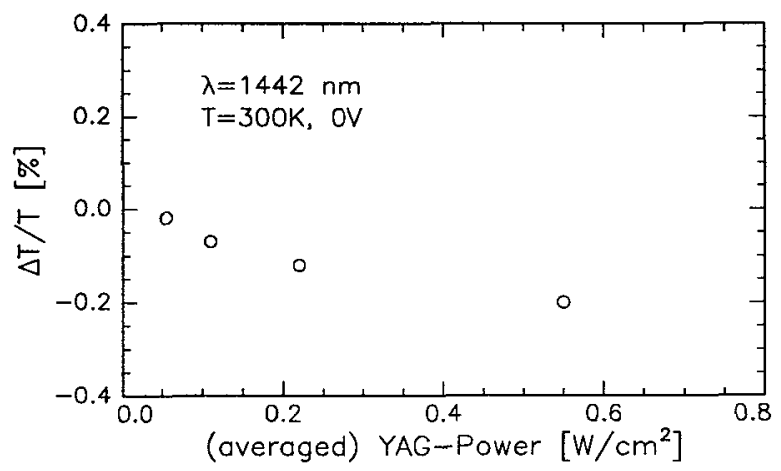

Figure 2: Power density modulated differential transmission signal for excitation power densities lower than $0.6 \mathrm{~W} / \mathrm{cm}^{2}$. No external voltage is applied. Increasing YAG-power the signal decreases. This is caused by the blue shift of the exciton. 


\section{Dynamic Pump-Probe Measurements}

For our pump-probe measurements we used $5 \mathrm{ps}$ (Nd-YAG) pump pulses and probed (0.5ps) with a fixed wavelength on the high energy side of the heavy hole exciton. Both pump and probe pulses were focused through a lensed fiber perpendicular to the epilayers.

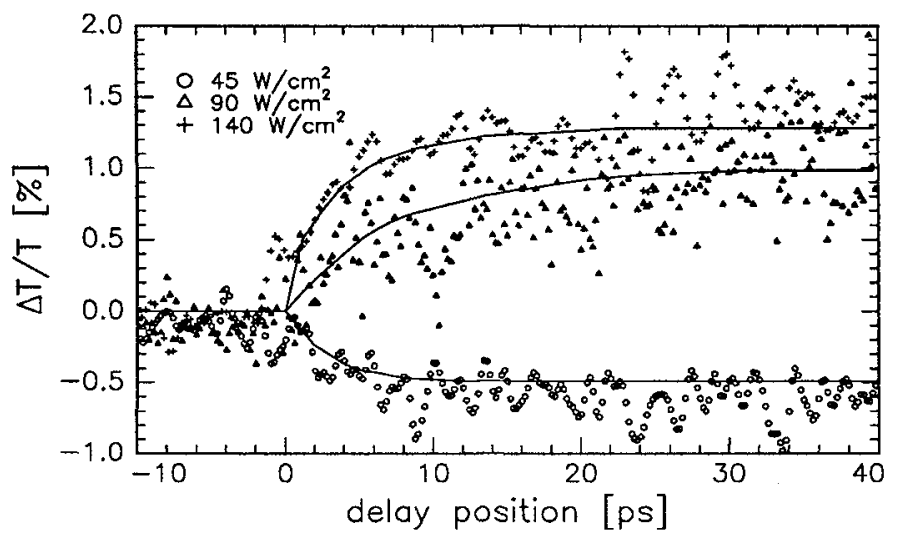

Figure 3: Dynamic differential transmission signal for different excitation power densities. At about $0 p s$ the excitation occurs. The negative and the positive sign of the differential transmission signal indicates field screening and exciton saturation, respectively. In addition eye guides are shown.

The behaviour of our pump-probe measurements up to the excitation power densities of $140 \mathrm{~W} / \mathrm{cm}^{2}$ is shown in Fig.3. In the case of $45 \mathrm{~mW} / \mathrm{cm}^{2}$ we find a negative differential transmission change and for the higher excitations a positive transmission change.

The negative sign at $45 \mathrm{~mW} / \mathrm{cm}^{2}$ of the pump-induced probe transmission signal indicates again a field screening induced blue shift in the exciton energy with increasing excitation power. Before the pump pulse excites the device the intrinsic electric field determines the position of the exciton. If the pump puls excites the MQW region $\left(t_{\text {delay }}>0 \mathrm{ps}\right)$ the photogenerated carriers are screening the intrinsic field and the exciton shifts to higher energies. Because we probed our MQW structure on the high energy side of the exciton the observed decrease of the transmission can be explained. At excitation power densities higher than $50 \mathrm{~W} / \mathrm{cm}^{2}$ we observe an increase in transmission which we attribute to exciton saturation.

Looking at the rise time of these pump-probe measurements we find for the negative transmission change a little higher rise time $\left(t_{\text {rise }} \simeq 10 \pm 2 p s\right)$ than for the positive one $\left(t_{\text {rise }} \simeq 6 \pm 2 p s\right)$. This should be an indication for the different origin of the negative and positive transmission change. The longer rise time in the case of field screening can be explained by the additional carrier transport in the MWQ structure.

The power dependence of the maximum of the transmission change for the pump-probe measurements is shown in fig. 4. These measurements at high power excitation can be described with the exciton saturation model of Chemla [9]. The calculated power dependence also shown in fig. 4 agrees very well with the experimental results. This supports the assumption that exciton saturation is responible for the increase in transmission at high excitation power densities. The calculated exciton saturation intensity as defined by Chemla $[9]$ is $I_{S}=250 \mathrm{~W} / \mathrm{cm}^{2}$. 


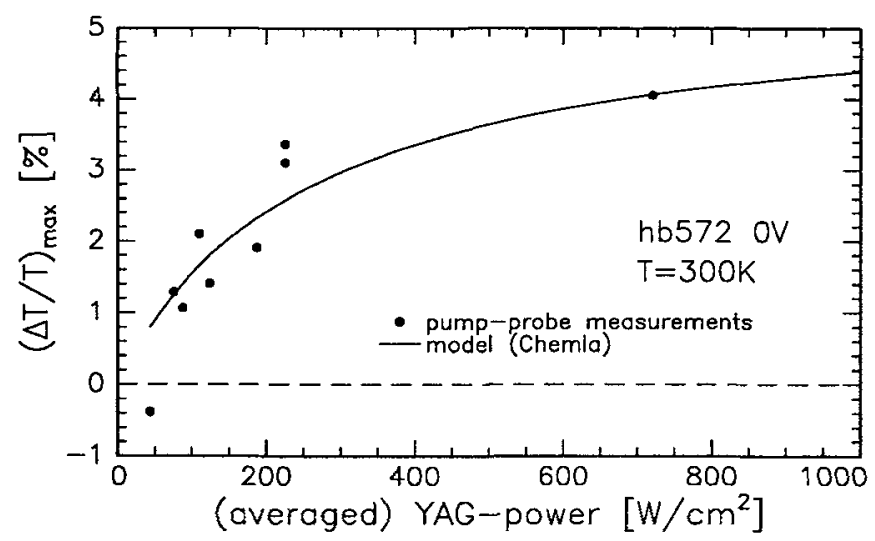

Figure 4: The transmission change at $(\lambda=1542 \mathrm{~nm})$ dynamic pump-probe measurements is shown over power density. Exciton saturation is observed at high power densities.

\section{Conclusion}

In conclusion, we investigated the excitation dependence of field screening and excitation saturation in InGaAs/InGaAsP MQW structures. Field screening reduces the electric field in the multi quantum well region which is shown in a blue shift of the exciton energy increasing excitation power. This effect dominates for excitation intensities lower than $50 \mathrm{~W} / \mathrm{cm}^{2}$. At higher power densities exciton saturation dominates. That means that the exciton absorption is extremly reduced and the differential transmission signal increases (fig. 4). We measured a saturation density of $250 \mathrm{~W} / \mathrm{cm}^{2}$ for this structure.

One of us (B. J. Hawdon) gratefully acknowledges the support of the Alexander von Humboldt Foundation. This research was supported by the Deutsche Bundespost Telekom.

[1] Thomas H. Wood, IEEE J.Lightwave Technology 6, 743 (1988).

[2] F. Devaux, E.Bigan, A. Ougazzaden, B. Pierre, F. Huet, M. Carre, A. Carenco, IEEE Photonics Technol. Lett. 4, 720 (1992).

[3] T. H. Wood, T. Y. Chang, J. Z. Pastalan, C. A. Burrus, Jun, N. J. Sauer and B. C. Johnson, Electr. Lett. 27, 257 (1991).

[4] T. H. Wood, J. Z. Pastalan, C. A. Burrus, B. C. Johnson, Appl.Phys.Lett. 57, 1081 (1990).

[5] B. J. Hawdon, T. Tütken, A. Hangleiter, R. W. Glew and J. E. A. Whiteaway, Electr. Lett. 8,

[6] A. Mark Fox, D. A. B. Miller,G. Livescu,J. E. Cunningham, W. Y. Jan. IEEE J. Quan. Elec. 27, 2281 (1991). 705 (1993).

[7] U. Koren, B. I. Miller, T. L. Koch, G. Eisenstein, R. S. Tucker, I. Bar-Joseph and D. S. Chemla, Appl. Phys. Lett. 51, 1132 (1987).

[8] M. Suzuki, H. Tanaka, S. Akiba Electronics Lett. 24, 1273 (1988).

[9] D. S. Chemla, D. A. B. Miller, P. W. Smith, A. C. Gossard and W. Wiegmann, IEEE. J. Quan. Elec. QE-20, 265 (1984). 